\title{
RETHINKING AND ADAPTING APPROACHES TO EDUCATION FOR SUSTAINABILITY TO ADDRESS CULTURAL AND BEHAVIOURAL CHANGE AND CHALLENGES
}

\author{
Deborah ANDREWS ${ }^{1}$, Elizabeth J. NEWTON ${ }^{2}$ and Ben LISHMAN ${ }^{1}$ \\ ${ }^{1}$ School of Engineering, London South Bank University \\ ${ }^{2}$ School of Applied Sciences, London South Bank University
}

\begin{abstract}
Designers and engineers have continually and simultaneously initiated, responded, and adapted to economic, social, and environmental change and challenges since practice began. Although they developed beneficial products, systems, and services, they were also pivotal to the linear economy and directly and indirectly contributed to environmental and social damage. Professionals are now being encouraged to address these problems through their practice. Design and engineering education was established to support industry by producing suitably prepared graduates; consequently, pedagogy has reflected professional practice and encouraged students to develop positive and optimum solutions to challenges. However, students and society as a whole are now facing unprecedented global environmental and societal problems that are affecting their behaviour, mental health, and ability to respond to these problems. Therefore, there is an urgent need to rethink and adapt current pedagogic practice in order to mitigate these issues, to ensure that sustainability remains core to design and engineering courses and that graduates transfer and embed this knowledge in the workplace. This paper first considers how designers and engineers have adapted practice in response to various drivers since the beginning of the professions; it then describes the role of general design and engineering education and that of design and education for sustainability. The final section describes an innovative strategy reverse psychology - and how it has been adapted to address these emerging challenges; the outcomes and impact of the approach are also illustrated through a case study and the reasons for success to date are analysed and discussed.
\end{abstract}

\section{Keywords: Education for sustainability, reverse psychology, deep learning}

\section{INTRODUCTION}

Continuity and adaptation have been inherent to the design and engineering design professions since their inception. For example, the invention of the steam engine and electrical systems initiated the first and second Industrial Revolutions from the middle of the $18^{\text {th }}$ century; the third (computing based) industrial revolution began in the 1950s and the fourth (cyber-physical) industrial revolution is now underway. While this illustrates continual innovation by the engineering, design, and other professions these innovations have also demanded adaptability. For example, activities and outputs associated with the $1^{\text {st }}$ and $2^{\text {nd }}$ Industrial Revolutions included mechanisation, the development of new energy systems and materials and the division of labour (which increased efficiency). These new manufacturing processes and materials also facilitated a shift from craft-based batch production to higher volume and mass production.

Design practice also emerged at this time in response to these changes although most 'design' was executed by architects, engineers, and artists. Some British practitioners (and most notably William Morris) rejected industrialisation in favour of the spiritual reward of manufacture by hand, but other practitioners embraced and adapted to the changes, and recognised the potential to develop new products and a new visual language. Christopher Dresser was one such individual; originally trained as a botanical illustrator he is regarded as one of the first independent industrial designers and he simultaneously championed design reform and adoption of modern manufacturing in the development of wallpaper, textiles, ceramics, glass, furniture, and metalware in the late 1800s and believed that form and aesthetics 
should derive from the materials and manufacturing process employed. Similarly, in 1907 the German architect and designer Peter Behrens is reported to have said that we refuse to duplicate handmade works, historical style forms and other materials for production. Both Dresser and Behrens designed for the expanding professional class consumer market, which saw unprecedented growth after World War One. Designers continued to exploit emerging technologies and materials until the 1929 stock market crash which led to a period of economic depression and unemployment. During the 1930s designers and engineers were encouraged to adapt in response to this situation as the economist Bernard London proposed 'planned obsolescence' as a strategy to restart the economy [1]. In this case they were asked to limit product life through use of non-durable materials, lack of spare parts and frequent changes in design. Notable examples include tungsten lightbulbs - which had a reasonable life span but were redesigned to fail after 1000 hours use - and GM and other car manufacturers introduced minor stylistic changes every year to encourage regular vehicle replacement by consumers who wanted to be seen as fashion leaders; these and other phenomena encouraged economic growth until World War II.

The social and economic impacts of this War were global, and the disruption of supply chains and resource shortages demanded further adaptions in approaches to design rather than designing for abundance. In the UK for example designers were required to maximise resource efficiency under the government led Utility scheme from 1943-1952, which ensured that clothing, furniture, and product designs were 'well-designed' and simultaneously durable while minimising use of materials. Unlike most of Europe and Asia, the USA was not invaded or bombed and consequently manufacturing capability remained intact throughout the War, and after the War the ability to supply goods rapidly returned to pre-war levels. Once again designers adapted to change and, in this case, they actively fuelled demand and, as epitomised by the American designer Brooks Stevens, they created 'the desire to own something a little newer and a little better, a little sooner than necessary' [2]. This approach and practice predominated in mainstream design throughout the following decades although there were some dissenters: for example Richard Buckminster Fuller (1895-1983) advocated 'ephemeralisation' (i.e. 'doing more with less') while Victor Papanek (1923-1998) publicly described the design profession as 'harmful' and 'a dangerous breed' responsible for creating a 'whole species of permanent garbage to clutter up the landscape, and by choosing materials and processes that pollute the air we breathe [3]. Consequently, his peers forced him to resign from their professional body, but he continued to promote prudence, and environmental, social, and moral responsibility. Another radical thinker, the architect Walter Stahel, also advocated resource prudence via cradle-to-cradle thinking from the 1970s. Like Buckminster Fuller and Papanek, his ideas were contrary to the mainstream until the early 1990s however when awareness of increasing demand on resources, waste and environmental degradation highlighted the need for a change in approach in line with 'sustainable development' as defined by the World Commission on Environment and Development in the 'Bruntland Report' [4]. Some designers responded positively to the challenge and adapted their practice and thus they continued to develop the ethos initiated by Buckminter Fuller, Papanek and Stahel as Design for Sustainability.

The evolution of the Design for Sustainability (DfS) and the sustainable design process and scope is summarised in a number of publications including Ceschin and Gaziulusoy in 2016 [5] who identify and describe ten key approaches that reflect the shift in focus from product to systemic design between 1990 and 2015. They are defined as green and eco-design, design for emotional durability and behaviour change, biomimicry, cradle-to-cradle and circular economy, Base of Pyramid, product-service innovation, socio-technical systems, and transitions. This shift is both an example of continuity in the discipline and of adaptation to change and increasing knowledge about the environment, social and economic factors that underpin sustainable development. Although some design and engineering professionals do not employ these philosophies, methods and strategies, many professionals and their clients are adapting and responding to and/or leading and creating positive change.

\section{THE ORIGINS OF DESIGN EDUCATION}

As noted above, early professional practitioners of design were either architects, artists, or engineers; however, developments in technology, materials and manufacture associated with the industrial revolution highlighted the need for more specialist design training around Europe and in the UK. The Royal Society for the Encouragement of Arts, Manufactures and Commerce (RSA) was founded in 1754 to ensure good links between the arts, manufacturing, and society and in 1762 an associated school was set up. Unfortunately, it was unsuccessful, but the government recognised the growing need for such link. In 1836 it established the Select Committee on Arts and Manufactures, as a result the first design 
(Normal) schools were set up near to manufacturing centres to prepare students for employment in and support industry and to develop 'good' design. Since then both design and engineering education have flourished globally and in 2017-18 for example in the UK alone there were 165,000 students on engineering and technology courses and 175,600 students on creative arts and design courses [6].

\section{EDUCATION AND DESIGN FOR SUSTAINABILITY}

In order to prepare students for employment, education has both adapted in response to and initiated developments in technology, its application and technology-human interaction in all disciplines, one of which is of course Design for Sustainability. At present there are only a couple of sustainable design courses in the UK, but many others include sustainability in the curriculum either as specialist modules or as assignments within modules. Like other design subjects, DfS has evolved to reflect and lead change and consequently it has broadened to consider products and service and system design.

Design for Sustainability is currently facing unprecedented challenges. These may derive from development in education such as a 'tick box culture' encouraged by modularisation, where students fail to transfer knowledge from one part of the course to another. They can also be associated with more profound personal factors as students and other individuals encounter existential problems and fears associated with climate crisis and global warming, environmental degradation, resource depletion and supply chain security, population growth and migration for example. These concerns are manifest as recently recognised behaviours, namely eco-fatigue, eco-anxiety, and eco-apathy. Eco-fatigue has been associated with sustainability action since the late 2000s [7] and more recently with sustainable tourism [8]. It is a condition in which people become tired of discussions about sustainability, are pessimistic about the future of sustainability and distrustful of sustainability-related business claims and triggers include too much and/or confusing information and negative practices such as green washing. Ecoanxiety is defined as a chronic or severe anxiety associated with fear of climatic and environmental catastrophe [9], and it can have a very adverse impact on mental health and well-being. Climate depression is also increasing among young people and people who work in sustainability-related professions. Finally Eco-apathy is associated with learned helplessness, a condition in which individuals feel so overwhelmed by the scale of a problem that they believe that they are incapable of making changes as an individual and therefore do nothing. These conditions are being exacerbated through use of social media and the internet where algorithms repeatedly present readers with similar and/or more extreme articles so they are deprived of balanced opinion and information.

As educators it is essential to respond and adapt to these emerging challenges and to develop pedagogic strategies that simultaneously mitigate these issues and ensure that sustainability continues as a core subject within design and engineering courses and ultimately in industry. This calls for an alternative to current pedagogic practice that actively provokes curiosity, is engaging, memorable, makes an impact and is enjoyable to ensure that students fully engage with education about and for sustainability in the immediate, mid, and long-term. It is equally important to empower students so they can deal with their negative feelings and improve their mental health and well-being and the following assignment was developed to meet these various criteria and outcomes.

\section{AN ALTERNATIVE PEDAGOGIC STRATEGY}

\subsection{The Assignment: Design your Future - your city your choice}

The assignment was part of the first year 'Sustainability Week' which was introduced to give all design students a good fundamental knowledge of the subject. Students were required to work in interdisciplinary (mixed PD and EPD) groups of 3 or 4 on a 4-day assignment and to develop an unsustainable design proposal. Each group worked on a different theme, namely food, water, transport, travel, energy production, buildings, resource use, health and leisure and they must 'trash' as many UN Sustainable Development Goals (SDGs) as possible. The following figures show examples of students' proposals. 

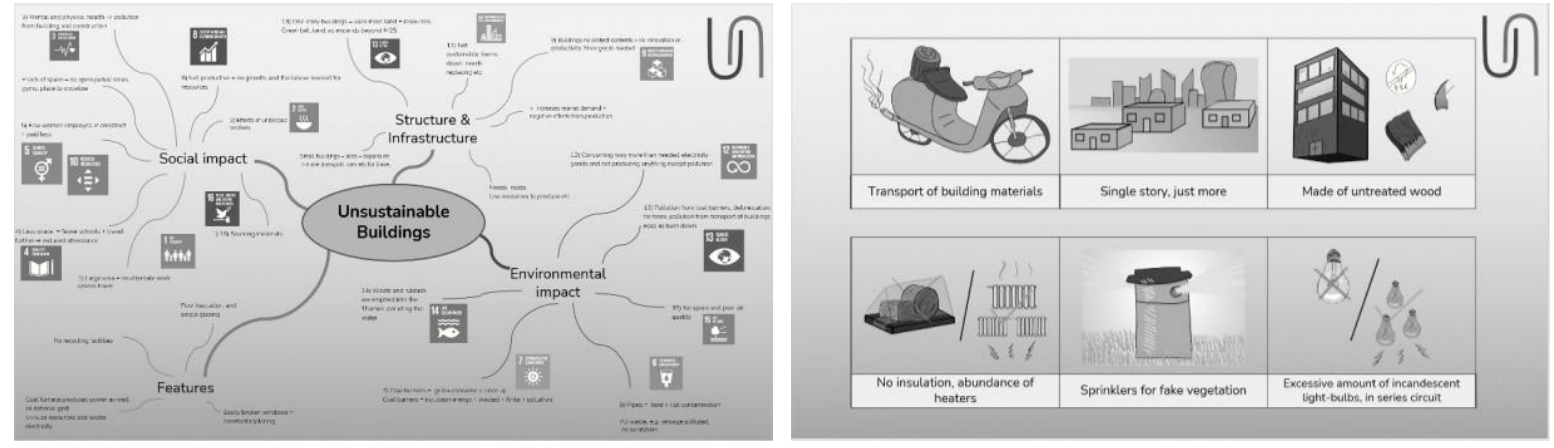

Figure 1. Unhaus - Unsustainable Buildings
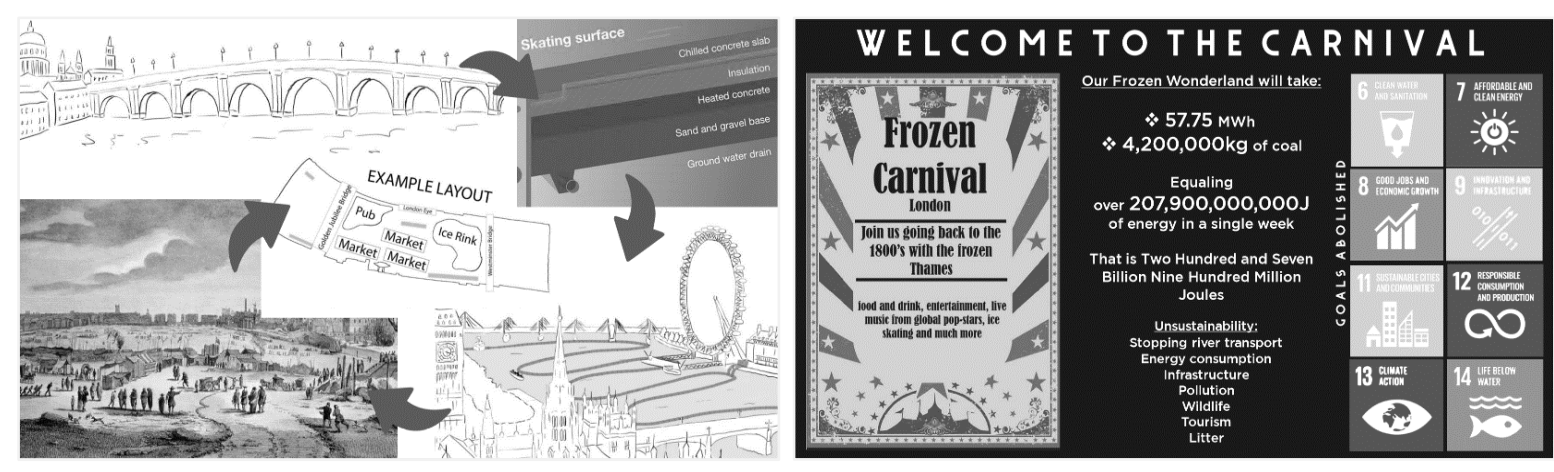

Figure 2. Frozen Carnival - Unsustainable Leisure
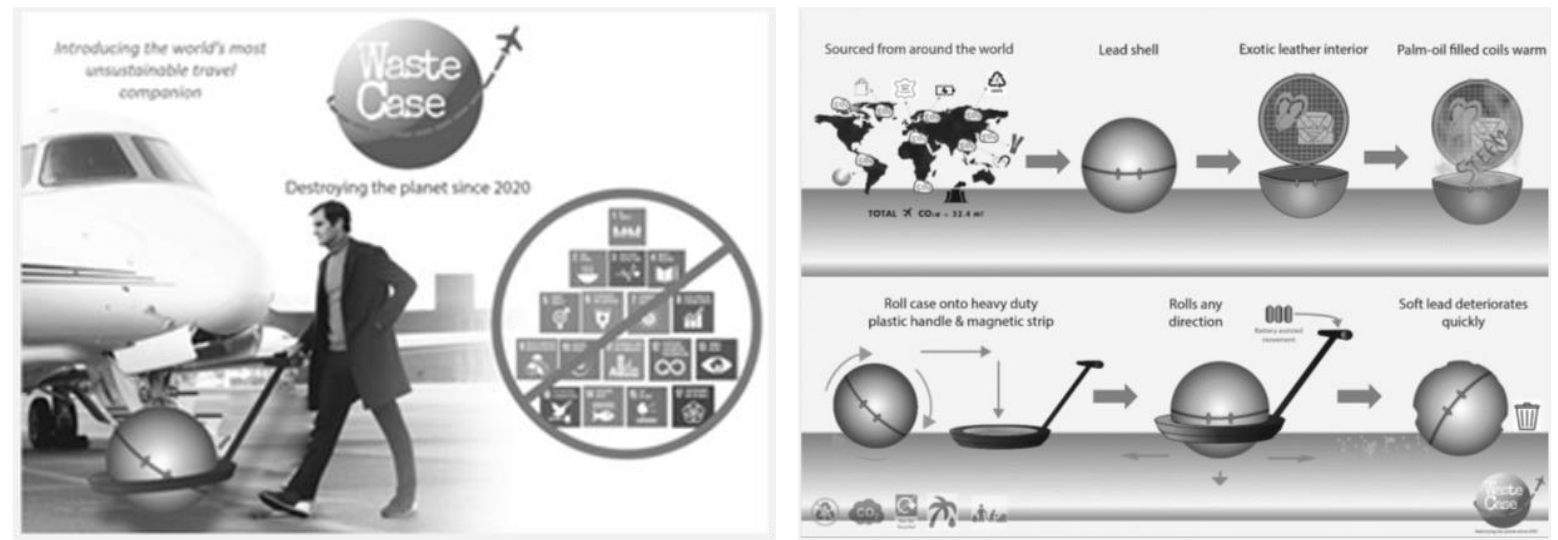

Figure 3. Waste Case - Unsustainable Travel

\subsection{Results}

The assignment was introduced in 2018 and has run three times and as illustrated by quantitative and qualitative review, it is proving to be increasingly successful. There has been an upward trend in results since 2018 , and while the quality of project output has improved, students also appear to be transferring and implementing what they have learnt to other assignments, modules, and course years. A simple participant survey also showed that $83 \%$ of respondents enjoyed the activity more than if they had been asked to just design an 'ordinary' or mainstream product. Furthermore $56 \%$ said that the approach had probably and 26\% said it had definitely deepened their understanding of sustainability and sustainable design more than a mainstream sustainable design assignment. Students were also asked to identify whether they had learnt about: (a) the UN SDGs, (b) current global challenges, (c) designers' responsibility to address the challenges, (d) designers' potential to address the challenges, (e) the effects of unsustainable design output and (f) the effects of sustainable design output. All students learnt about two or more of these points, and so learnt about all. Finally, 100\% of students said they would recommend that the project should run in the future. Anecdotal feedback was also positive and included comments like: 'although I ticked all from what I learned during the project I would like to learn more', 'I would explore more sustainable technology' and 'I found it a very helpful approach to find the most 
unsustainable product we could as reverse engineering it would give us the most sustainable product'. It is evident that the assignment has been successful to date; it is important to understand the reasons why this is so, and they are now discussed.

\section{REVERSE PSYCHOLOGY AND DEEP LEARNING}

The term 'reverse Psychology' refers to a manipulation whereby the opposite of what is being sought is asked for, the theory being that this will lead to people opting for the belief they think is being advocated against. A problem for this approach is when the person realizes they are being manipulated and takes revenge by following the original suggestion (the opposite of what is desired). Typical examples are a parent trying to persuade a child to eat a particular vegetable by telling them 'I don't think you would be able to eat it all' rather than the 'please try some' approach. This approach is used in marketing [10], where there has been an increase in the use of reverse psychology to engage the consumer who may be inured to conventional marketing principles. An extensive search using various key terms has failed to find any academic papers discussing the use of reverse psychology in teaching but research by Craik \& Lockert in 1972 [11] explains why it is successful. They proposed a Levels of Processing Model which suggests that the deeper information is processed, the more elaborate and longer lasting the recall of that information will be. If information is more readily available, then it becomes easier to consider and understand. A student-centred approach to learning, sometimes called active learning, has been shown to increase the learner's feeling of being an active participant in the process and has an emphasis on deep learning and understanding. This suggests that being an active learner will encourage the student to process what they are learning at a deeper level, increasing their understanding of the topic. The novel approach of this project was to use reverse psychology to encourage deeper processing of the information. Traditionally, students are taught about the right way to do things and then put that knowledge into practice.

This paper outlines a completely different approach. Whilst the aim of most educators is to encourage students to follow the rules in order to learn, in this instance the students were told to break as many rules as possible in order that they met the learning objectives of understanding the rules; using reverse psychology to obtain the desired outcome. They were asked to come up with designs which negated as many SDGs as possible. The theory was that it would not be possible to break the rules, unless they knew what the rules were in the first place. In order to break the rules, the learners needed to think about them at a much deeper level in order to understand how to break them as illustrated in Figures 1, 2 and 3 , which present example design concepts for unsustainable buildings, leisure, and travel. The students began the project by reviewing and learning about the aims and scope of individual SDGs. They then brainstormed ways of undermining and counter-acting them such as damage to climate, health, and ecosystems. This enabled them to identify criteria such as material types, durability, and toxicity and how these factors would adversely affect e.g., miners, makers, and consumers; they also considered energy generation, fuels and emissions, types of transport, efficiencies and associated impact on the environment and eco-systems and social factors such as slavery, child labour and low wages and considered whole life cycles including unregulated product disassembly and disposal. This helped them to understand the broader implications of and the complex inter-relationship between design decisions and the SDGs and they made sure that their individual design choices adversely impacted on as many SDGs as possible. For example: the Unhaus proposal uses the least efficient highly polluting means of transport to carry materials to site; the buildings endanger residents because the timber has not been fireproofed, and eco-systems are destroyed through high land-use while water and energy are wasted through use of garden sprinklers and tungsten lighting. The Frozen Carnival replicates historical festivals but in this case the river has to be frozen artificially which requires a lot of fossil-fuel generated energy to damage the climate; food and drink are sold in single use packaging and waste is dropped through holes in the ice which damage the local eco-systems and contribute to ocean plastics. Finally Waste Case perfectly addresses unsustainable travel theme in that the case is made by children and poorly paid workers from soft lead which only lasts for one journey; use of lead also damages health, learning potential and the environment, while low wages prevent children from attending school. It is lined with fur from endangered animals, and it is very heavy and requires high energy inputs for transportation. The traveller also uses a private jet for local and long-haul travel, all of which directly and indirectly negate most SDGs.

While this looks positive, it is yet to be determined whether this approach will successfully translate to other disciplines, which warrants further research. Furthermore, it is essential that students understand 
the true nature of the approach which is to enhance their knowledge of sustainability and that they clearly explain this in their portfolios and at interviews.

\section{CONCLUSIONS}

This paper briefly describes how designers and engineers have adapted practice and output in response to technical, social, economic, and environmental factors since the first industrial revolution. It also explains that the primary role of education was to prepare students for employment, and therefore that courses and curricula reflected and were adapted in line with professional practice. However recent environmental phenomena have initiated new behaviours and culture that demand an alternative approach that does not reflect the best of current professional practice and is contrary to good practice. In this case the innovative use of reverse Psychology in an educational context is a positive adaption to address challenges facing many young people and students. It is clear from the level of student engagement and the meeting of the learning objectives that this method worked well to encourage a deeper processing of the information about both the UN Sustainable Development Goals and sustainability in general. One advantage of this method is that the deeper learning means it is much more likely that this learned knowledge will remain and be applied long after the students graduate, thus having a positive impact in the quest for a more sustainable future. It was clear from the student comments that they found the assignment brief initially surprising because they were asked to break the rules, which is the opposite of traditional teaching practices. They also found the brief challenging, but this only served to make them engage beyond a superficial 'how do I pass' level and become the active learners they needed to be. Finally, when students enjoy the learning process, they are more likely to engage at a deeper level and to spend time outside the classroom thinking about the subject holistically and participate in self-directed study.

\section{REFERENCES}

[1] London B. Ending the Depression Through Planned Obsolescence. 1932. New York. Available: https://babel.hathitrust.org/cgi/pt?id=wu.89097035273\&view=1up\&seq=7 [Accessed 21.1.2021].

[2] Stevens B. in Adamson G. Industrial Strength Design: How Brooks Stevens Shaped your World. 2003. Cambridge, MA: MIT Press.

[3] Papanek V. in Rawsthorne A. Victor Papanek, an early champion of good sense. New York Times, 15 May 2011. Available at: New York Times.

[4] WCED (World Commission on Environment and Development) Our Common Future 1987. Oxford University Press, Oxford, New York.

[5] Ceschin F. and Gaziulusoy I. Evolution of design for sustainability: From product design to design for system innovations and transitions Design Studies 47, 2016, pp. 118-163.

[6] Universities UK. Patterns and Trends in UK Higher Education 2018 https://universitiesuk.ac.uk/facts-and-stats/data-and-analysis/Documents/patterns-and-trends-inuk-higher-education-2018.pdf . [Accessed on 21.1.2021].

[7] Turtle E. Green Fatigue and Eco Anxiety. 2008 https://archives.cjr.org/the_observatory/green_fatigue_and_eco_anxiety.php [Accessed 3.3.2019].

[8] Moscardo G. and Pearce J. Eco-fatigue and its potential impact on sustainable tourist experiences. In: Proceedings of the BEST EN Think Tank XIX. pp. 140-164. From: BEST EN Think Tank XIX: Creating Sustainable Tourist Experiences, 30 June - 3 July 2019, San Francisco, CA, USA.

[9] Clayton S., Manning C. M., Krygsman K. and Speiser M. Mental Health and Our Changing Climate: Impacts, Implications, and Guidance. 2017 Washington, D.C.: American Psychological Association, and ecoAmerica. https://www.apa.org/news/press/releases/2017/03/mental-healthclimate.pdf [Accessed 3.3.2019].

[10] Sinha J. and Foscht T. Reverse psychology tactics in contemporary marketing, November 2016 The Marketing Review 16(3):343-353 DOI: 10.1362/146934716X14636478977872.

[11] Craik F. I. M. and Lockhart R. S. Levels of processing: A framework for memory research, Journal of Verbal Learning and Verbal Behaviour, 11, Issue 6, 1972, pp 671-684. 